\title{
Social Media Contribution to the Promotion of Digital Citizenship among Female Students at Imam Mohammed bin Saud Islamic University in Riyadh
}

\author{
Khaled Ibrahim Alturki ${ }^{1} \&$ Wafa Owaydhah Alharbi ${ }^{2}$ \\ ${ }^{1}$ Assistant Professor, Faculty of Social Sciences, Imam Mohammed bin Saud Islamic University, Riyadh, Saudi \\ Arabia \\ ${ }^{2}$ Ministry of Education, Riyadh, Saudi Arabia \\ Correspondence: Wafa Owaydhah Alharbi, Ministry of Education, Riyadh, Saudi Arabia. Tel: 966-503-202-403. \\ E-mail: kaltrk@hotmail.com
}

Received: October 27, 2017 Accepted: December 5, 2017 Online Published: December 9, 2017

doi: $10.5539 /$ elt.v11n $1 \mathrm{p} 80$

URL: http://doi.org/10.5539/elt.v11n1p80

\begin{abstract}
The study aimed to identify the degree of social media contribution to reinforcing digital citizenship meaning from the viewpoint of female students at Imam Mohammed bin Saud Islamic University in Riyadh. The study was an attempt to answer the following two questions in order to achieve the objectives of the study: To which extent does SnapChat site reinforce digital citizenship meaning as the female students of Imam Mohammed bin Saud Islamic University in Riyadh understand? What degree of contribution does Twitter site strengthen digital citizenship meaning as the female students of the same University understand? The researcher used the survey descriptive method to answer these questions. The tool of this study was a questionnaire, and the society of the study was the female students of Imam Mohammed bin Saud Islamic University in Riyadh understand and the study was applied on 100 female students. Using the proper statistical tools to analyze the collected data, the study revealed that the SnapChat site as well as the Twitter site contribute to reinforce digital citizenship meaning as the female students of Imam Mohammed bin Saud Islamic University in Riyadh understand. Both sites have added technology skills to the students such as publishing quickly, expression, freedom to express an opinion, and communicate quickly with all over the world. The SnapChat and Twitter have no digital security feature in terms of positioning, ease of penetration and save the private clips. The study concluded with a set of recommendations and suggestions.
\end{abstract}

Keywords: social media, digital citizenship, female students

\section{Introduction}

This age is the age of communication media which grows quickly and constantly, therefore it requires many different skills in order to cope with its variable and multiple activities and interactions. Moreover, it is the age of global openness and unlimited and technological development. It has become necessary to make advantages of such technological and digital advances in the field of education so that the new generation can easily adapt and cope with this new technological and digital world.

Communication media contains multiple sites in which a learner can conveniently find what he needs. These sites are easy to be accessed through an application that can be downloaded to a mobile or iPad, where the learner can get access to the whole world. Besides, he can be involved in broadcasting news, commenting on it and giving his opinion about it. This has led to the emergence of the so-called social networks or as (Shakra, 2014, p. 53) calls them 'the new media'.

Today, the use of virtual community for achieving interests is predominated, as people can finish their jobs through digital technology. This transformation requires to change the way of dealing with this generation who has been lost in an unlimited world of technological dominance, it also requires to get a life balance by showing the standards and ways to deal with digital technology, to become a digital citizen who knows his rights as well as his duties, protects himself and his information and becomes a good citizen.

This study aimed to identify the contribution degree of SnapChat and Twitter in promoting the concept of digital 
citizenship among the female students of Imam Mohammed bin Saud Islamic University in Riyadh.

\subsection{Importance of the Problem of the Study}

Under the technological development, new specifications of citizenship appeared that called digital citizenship or digital citizen which means that the citizen became capable of learning, shopping, getting friendships digitally, also he can create social relationships via digital technology. In the light of this wide use of community of technology, it becomes necessary to enhance the positive aspects of the technology, take advantage of them and direct the society to achieve the digital citizenship standards.

This study is an attempt to take the advantage of social networks as they are the most popular sites among learners communities and direct them to enhance the concept of digital citizenship. SnapChat and Twitter are the most important widespread sites of social networks in the university community, which in some way contribute to enhance the concept of digital citizenship. More importantly, a survey was made on female students in the faculty of social sciences at Imam Muhammad bin Saud Islamic University on the use of social networks and their importance for the students. The survey showed that SnapChat and Twitter are the most interesting ones among students. As a response to the previous studies and according to the importance of this aspect, the current study seeks to recognize the degree of contribution of some social networks in promoting the concept of digital citizenship from the viewpoint of female students at Imam Mohammed bin Saud Islamic University in Riyadh. Moreover, the present study comes as a response to scientific conferences which calls for the deployment of technological awareness among the learners. This study provides suggestions about instilling the values of digital citizenship among female students. In addition, it helps to create space for other studies in the area of promoting the concept of digital citizenship among students. This study could be also the core for others researchers to study the digital citizenship subject from other aspects. Also, it may provide new ideas for taking advantage of social networks to serve education. Besides, this research may help to deploy the digital citizenship culture among female students.

\subsection{Relevant Scholarship}

The educational community is the essential foundation which we have to start with to spread this knowledge and instill good habits to benefit from the technology for serving themselves and the society. According to (Lenhart, Purcell, Smith, \& Zickuhr, 2010) study which focused on social networks in order to understand the experiences faced by teenagers, how to handle the negative behavior when they see or experience it, and its consequences for the direction of the majority of teenagers to use these networks of different types of uses, besides giving recommendations about paying big attention to this subject in future studies. In this context, (Maslamani, 2014) emphasized the increase of student direction for using technology in its different applications, also the education needs to increase instilling digital citizenship values in students and to face the negative impacts of digital technology. A study by Ribble revealed that the digital world has changed how the people act and do their jobs as citizens in the real world. Users live, work and interact in only in the real world, but also in through the digital and virtual one. So, teachers have to prepare students to live in unlimited concrete world and help them to learn how to work with others (Ribble, 2012, p. 40). Another study by Trilling and Fadel demonstrated that:

This current century is taking us to the knowledge era which has started recently, and that characterized with the global interdependence of cognitive work, global markets, citizens linked to each other remotely and integrated cultural traditions. The twenty first century requires a set of new responses" (Trilling \& Fadel, 2009, p. 16).

Shakra also addressed the new media finding that:

New services and models of media lead to the emergence and development of communication media content automatically or semi- automatically in the media process by using modern electronic technology resulting from the integration of information and communication technology as media vectors loaded with its potential form and content, also includes the signals, information, images and the voices which form the media materials. (Shakra, 2014, p. 53)

A study by Manjaji, 2014 entitled 'Six SnapChat Experiments to Engage Students' also a dressed the subject under study. Wilson, 2015 in his 'research 'Using SnapChat in Higher Education' talked about the use of social network among students.

Thus, tis study draw on the existing scholarship relevant to the use of social networks among students and utilizes these study to investigate the issue of the contribution degree of two social networks, SnapChat and Twitter, in promoting the concept of digital citizenship viewed by female students at Imam Mohammed bin Saud Islamic University in Riyadh as these two sites are the more common and preferred by the students according to the conducted survey. This study draw on previous literature to fills a gap in the academic field that there is no 
previous study has far addressed this issue since this issue is a new phenomenon in the academic environment and particularly among female students in the universities in Saudi Arabia. The study provides new ideas for taking the advantage of social networks to serve education and questions to what extent these the two sites contribute to enhance the concept of digital citizenship among female students at Imam Mohammed bin Saud Islamic University in Riyadh. Theoretically, the current study utilized the previous studies in building tools, theoretical frameworks and drew on the results and recommendations of the previous studies and linked them to the results of the current study.

\subsection{Questions of the Study}

This study attempts to answer a basic question: what is the contribution degree of some social networks in promoting the concept of digital citizenship viewed by female students at Imam Mohammed bin Saud Islamic University in Riyadh? This question leads to the following two questions: what is the contribution degree of Snapchat in promoting the concept of digital citizenship from the viewpoint of female students at Imam Mohammed bin Saud Islamic University in Riyadh? And what is the contribution degree of Twitter in promoting the concept of digital citizenship from the viewpoint of female students at Imam Mohammed bin Saud Islamic University in Riyadh?

\section{Method}

\subsection{Conceptual and Operational Definitions}

Social networks is defined by Shakra $(2014$, p. 60$)$ as "they are websites on the internet, the one who has an account in them can communicate by multiple ways (writing, sound, video) with whom he wants, whether with those who have an account in those websites, or with ordinary people such as old friends, business associates, costumers or with major contacts such as companies or institutions, whatever ideas, opinions or feelings, or maybe for a particular product and for finishing works in that digital community. The operational definition of the Twitter and SnapChat are two of social media networks which are used by female students of the Islamic University of Imam Mohammed Bin Saud and their role in improving the concept of digital citizenship. Citizenship is another concept used in this study which is defined as a combined and multi-dimensional concept that includes legal, cultural, social and political elements that gives the citizen certain right duties. It gives him a strong sense of identity and social bond as well. The operational definition of the researcher is that citizenship is all the duties and rights that pertain every member of the society, those which begot to him the feeling of union and the desire of participation. Digital citizenship as one of the variables of the study is defined by Maslamani $(2014$, p. 23) as a method that helps teachers and leaders to understand what the students should know so that they can use technology as best as possible, and instead on focusing of the process digital connection with information, it takes into consideration the conduct and responsibilities which are related to the digital use of these information. The operational definition of the researchers, the digital citizenship means here the perfect use of Twitter and SnapChat by the girl students of the Islamic University of Imam Mohammed Bin Saud.

\subsection{Participant Characteristics}

This study is limited to Female students in the Faculty of Social Sciences at Imam Mohammed bin Saud Islamic University in Riyadh, which includes four departments (Social Work, Psychology, Sociology and Special Education). It was applied in the the second semester of the year 1436/1437 AH in order to identify the contribution of the two sites of social networks; SnapChat and Twitter, and their roles in promoting the concept of digital citizenship.

\subsection{Sampling Procedures}

The sample of the study was a purposive sample method for several reasons: the difficulty to access the statements of the students. Moreover, the students can respond easily and conveniently with the researcher as she is one of the college community. The study sample is taken from four departments (Social Work, Psychology, Sociology, Special Education) of Social Science Faculty. It was applied in the second semester of the year 1436/ $1437 \mathrm{AH}$ after taking the official permission of the department and taking the official facilities. The intended study community is female students in social science college at Imam Mohammed bin Saud Islamic University. The number of respondents in this study was 120 students, taken from the four departments. There were 20 questionnaires that had been excluded from the analysis because they were invalid and because of the incomplete responses that were not answered seriously.

\subsubsection{Sample Size, and Their Distribution}

The number of respondents in this study was 100 female students after excluding 20 invalid responses. The distribution of the sample members was as shown in (Table 1) according to the field of the study of the 
respondents.

Table 1 . The study sample distribution according to specialization variable

\begin{tabular}{lll}
\hline Specialization & Repetition & Percentage \\
\hline Social Work & 2 & 2.0 \\
Special Education & 4 & 4.0 \\
Sociology & 55 & 55.0 \\
Psychology & 39 & 39.0 \\
Total & 100 & $100 \%$ \\
\hline
\end{tabular}

\subsubsection{Measures}

Written questionnaire was used as the tool for this study, and has been applied and presented to the arbitrators to determine the veracity of statements and achieve the standards of digital citizenship and taking them out in the final form. It was taken into account that responses scores to be according to Likert quadruple scale, as each phase of the questionnaire has the following assessment (always, sometimes, rarely, never). For the purpose of processing, each phrase in the questionnaire was given a specific value as following (always) 4 scores, (sometimes) 3 scores, (rarely) two scores and (never) one score.

To enhance the quality of the questionnaire the validity of the tool, Internal consistency and reliability were made. First, Virtual Validity and Sincerity of Arbitrators (Face \& Trustees Validity) was done. The study tool was introduced to arbitrators, they were 10 persons from different disciplines, to give their views on the validity and thoroughness of the questionnaire and clarity of its clauses, and based on what has been referred to the amendment was done. Second, internal consistency was done that after confirming virtual validity of the questionnaire by researcher, she applied it in the field on the study sample, and after collecting all questionnaires the researcher encodes and entered data on a computer device by using statistical package for social sciences. Then, she calculated the Pearson correlation coefficient 'Pearson Correlation' to know the inner validity of the questionnaire clauses by calculating the correlation coefficient between the scores of each clause by total score of the phase that clause belongs to. Next, the reliability of the tool was verified. Stability refers to confirming the effectiveness of the tool in obtaining data that reflects the accuracy and objectivity of the study variables. Ensuring the stability of the study tool is aiming to ensure the ability of the tool to get the same data from the respondents in the case of repeated application of the tool, and in order to ensure the stability of the questionnaire, the study has utilized an alpha Cronbach coefficient (Cronbach Alpha).

\subsubsection{Research Design}

The researcher used the descriptive survey, as it is the most suitable method for this study. First, a survey was conducted on female students in four departments in the faculty of social sciences which are Social work, Special Education, Sociology, and Psychology at Imam Muhammad bin Saud Islamic University on the use of social networks and their importance for the students. The survey was open questionnaire which targeted 120 female students before the exclusion of 20 invalid responses. The survey contained five questions: Which social networks in which the student has an account? Which social networks the student visit daily? Which social networks in which the student participate? Which social networks the student finds more useful? Which social networks in which the student feels most convenient to express herself? Using descriptive quantitative method and calculation the Data Arry style and Frequency distribution, the responses were divided by the total number of the respondents multiplied by 100 to get the percentage. Out of 17 social networks given in the responses, the result led to choosing that SnapChat and Twitter as the independent variables of the study being the most widespread and used by the students. As the digital citizenship is the dependent variable of the study, the theoretical available material was utilized leading to selecting the model that determine Respect, Education, and Security as the main phases of digital citizenship. Each of these phases include three dimensions. On the basis of this survey, the final questionnaire was build. The questionnaire was of two types closed and open to get more detailed information about the most important advantages, disadvantages, and skills that the two sites can add to promote the concept of the digital citizenship. The closed questionnaire consisted of 30 clauses and the open on consisted of 3 questions. After the assessment by the arbitrators, checking the validity, internal consistency, and reliability, the questionnaire was distributed to the members and number of the sample study, 100 female 
students from the four departments in the faculty of social sciences which are Social work, Special Education, Sociology, and Psychology at Imam Muhammad bin Saud Islamic University to achieve the objectives by answering the two questions of the study. Statistical Package for Social Sciences was used to analyze the collected data. Frequencies and percentages, Arithmetic mean, Weighted arithmetic mean, Standard deviation, Person correlation coefficient, and Cronbach Alpha coefficient were used to measure the variables quantitatively.

\subsubsection{Statistical Processing Methods}

The following statistical measures were calculated in the study Frequencies and percentages, Arithmetic mean, Weighted arithmetic mean, Standard deviation, Person correlation coefficient, and Cronbach Alpha coefficient. Frequencies and percentages were used to identify the field of the study of the individuals included in the study sample and to determine their responses to the main phases included in the study. Arithmetic Mean was used in order to identify how high or low are the responses of the study individuals for each main clause of variables of the study, according to the questionnaire phases. Knowing that this is useful to organize the clauses by a higher weighted arithmetic mean. Weighted Arithmetic Mean was calculated in order to identify how high or low are the responses the study individuals for the main phases (mean averages of clauses). Knowing that this is useful to organize the phases according to the highest weighted arithmetic mean. Standard Deviation was used in order to identify the extent of the deviation and dispersion of responses of study individuals for each main clause of variables of the study, and for the arithmetic mean of each mail phase. It is noted that the standard deviation shows the dispersion in the responses of study individuals for each clause in the study variables, besides, the main phases, as the closer the value to zero, the more the responses fixed and the lower its dispersion in the scale Person Correlation Coefficient was used in order to identify the degree of correlation between the questionnaire clauses and the phase or dimension which is belong to and the total score of the questionnaire. Cronbach Alpha Coefficient was calculated in order to test the reliability of study tool.

\section{Results and Discussion}

\subsection{Statistics and Data Analysis}

Table 2. Correlation coefficients between each score of each phase in the questionnaire with total score of the dimension which it belongs to

\begin{tabular}{|c|c|c|c|}
\hline Sentence No & Correlation Coefficient & Sentence No & Correlation Coefficient \\
\hline \multicolumn{2}{|c|}{ Contribution Degree of Twitter } & \multicolumn{2}{|c|}{ Contribution Degree of SnapChat } \\
\hline \multicolumn{2}{|c|}{ First Phase: Respect } & \multicolumn{2}{|c|}{ First Phase: Respect } \\
\hline \multicolumn{2}{|c|}{ First Dimension: Digital Access } & \multicolumn{2}{|c|}{ First Dimension: Digital Access } \\
\hline 1 & $0.636^{* *}$ & 1 & $0.530^{* *}$ \\
\hline 5 & $0.646^{* *}$ & 5 & $0.743^{* *}$ \\
\hline 6 & $0.752^{* *}$ & 6 & $0.739^{* *}$ \\
\hline 23 & $0.495^{* *}$ & 23 & $0.587 * *$ \\
\hline \multicolumn{2}{|c|}{ Second Dimension: Digital Law } & \multicolumn{2}{|c|}{ Second Dimension: Digital Law } \\
\hline 3 & $0.630^{* *}$ & 3 & $0.580 * *$ \\
\hline 25 & $0.669 * *$ & 25 & $0.632 * *$ \\
\hline 30 & $0.672 * *$ & 30 & $0.691 * *$ \\
\hline \multicolumn{2}{|c|}{ Third Dimension: Digital Suitability } & \multicolumn{2}{|c|}{ Third Dimension: Digital Suitability } \\
\hline 12 & $0.660^{* *}$ & 12 & $0.716^{* *}$ \\
\hline 13 & $0.704 * *$ & 13 & $0.733^{* *}$ \\
\hline 17 & $0.644 * *$ & 17 & $0.642 * *$ \\
\hline \multicolumn{2}{|c|}{ Second Phase: Education } & \multicolumn{2}{|c|}{ Second Phase: Education } \\
\hline \multicolumn{2}{|c|}{ First Dimension: Digital Literacy } & \multicolumn{2}{|c|}{ First Dimension: Digital Literacy } \\
\hline
\end{tabular}




\begin{tabular}{|c|c|c|c|}
\hline 9 & $0.681 * *$ & 9 & $0.768 * *$ \\
\hline 11 & $0.740 * *$ & 11 & $0.690 * *$ \\
\hline 21 & $0.505 * *$ & 21 & $0.516 * *$ \\
\hline \multicolumn{2}{|c|}{ Second Dimension: Digital Trade } & \multicolumn{2}{|c|}{ Second Dimension: Digital Trade } \\
\hline 8 & $0.851 * *$ & 8 & $0.874 * *$ \\
\hline 24 & $0.828 * *$ & 24 & $0.870 * *$ \\
\hline \multicolumn{2}{|c|}{ Third Dimension: Digital Connection } & \multicolumn{2}{|c|}{ Third Dimension: Digital Connection } \\
\hline 7 & $0.505 * *$ & 7 & $0.454 * *$ \\
\hline 15 & $0.596 * *$ & 15 & $0.675 * *$ \\
\hline 19 & $0.507 * *$ & 19 & $0.555 * *$ \\
\hline 20 & $0.651 * *$ & 20 & $0.558 * *$ \\
\hline 28 & $0.481 * *$ & 28 & $0.449 * *$ \\
\hline \multicolumn{2}{|c|}{ Third Phase: Security } & \multicolumn{2}{|l|}{ Third Phase: Security } \\
\hline \multicolumn{2}{|c|}{ First Dimension: Digital Rights and Responsibilities } & \multicolumn{2}{|c|}{ Responsibilities } \\
\hline 4 & $0.580 * *$ & 4 & $0.610^{* *}$ \\
\hline 18 & $0.570 * *$ & 18 & $0.685 * *$ \\
\hline 22 & $0.424 * *$ & 22 & $0.609 * *$ \\
\hline 27 & $0.654 * *$ & 28 & $0.615 * *$ \\
\hline \multicolumn{2}{|c|}{ Second Dimension: Digital Security and Safety } & \multicolumn{2}{|c|}{ Second Dimension: Digital Security and Safety } \\
\hline 10 & $0.542 * *$ & 10 & $0.523 * *$ \\
\hline 16 & $0.768 * *$ & 16 & $0.723 * *$ \\
\hline 29 & $0.800 * *$ & 29 & $0.839 * *$ \\
\hline \multicolumn{2}{|c|}{ Third Dimension: Digital health and wellbeing } & \multicolumn{2}{|c|}{ Third Dimension: Digital health and wellbeing } \\
\hline 2 & $0.657 * *$ & 2 & $0.486 * *$ \\
\hline 14 & $0.602 * *$ & 14 & $0.644 * *$ \\
\hline 26 & $0.597 * *$ & 26 & $0.638 * *$ \\
\hline
\end{tabular}

** Function 20 at level 0.01 or less. ** Function at level 0.05 or less.

The results in Table 2. reveal that the correlation between clauses and the total degree of the dimension to which it belongs functions at a level of significance 0.01 or 0.05 or less, all of them are positive values. This indicates that there is high degree of internal consistency and there is correlation between the dimensions and their clauses, which reflects high degree of validity of scale clauses.

Table 3. Correlation coefficients between each dimension in the questionnaire with total score of the phase.

\begin{tabular}{llll}
\hline \multicolumn{2}{l}{ Contribution Degree of Twitter } & \multicolumn{2}{l}{ Contribution Degree of SnapChat } \\
\hline Firstly: Respect Phase & & Firstly: First Phase: Respect \\
\hline Dimension & Correlation Coefficient & Dimension & Correlation Coefficient \\
\hline Digital Access & $0.635^{* *}$ & Digital Access & $0.715^{* *}$ \\
\hline Digital Law & $0.795^{* *}$ & Digital Law & $0.715^{* *}$ \\
\hline
\end{tabular}




\begin{tabular}{|c|c|c|c|}
\hline Digital Suitability & $0.698^{* *}$ & $\begin{array}{l}\text { Digital } \\
\text { Suitability }\end{array}$ & $0.764 * *$ \\
\hline \multicolumn{2}{|l|}{ Secondly: Education Phase } & \multicolumn{2}{|c|}{ Secondly: The Second Phase: Education } \\
\hline Digital Literacy & $0.646^{* *}$ & Digital Literacy & $0.622 * *$ \\
\hline Digital Trade & $0.821^{* *}$ & Digital Trade & $0.889^{* *}$ \\
\hline Digital Connection & $0.684^{* *}$ & $\begin{array}{l}\text { Digital } \\
\text { Connection }\end{array}$ & $0.722 * *$ \\
\hline Thirdly: Security Phase & & Thirdly: Security Phas & \\
\hline $\begin{array}{l}\text { Digital Rights and } \\
\text { Responsibilities }\end{array}$ & $0.514 * *$ & $\begin{array}{l}\text { Digital Rights and } \\
\text { Responsibilities }\end{array}$ & $0.629 * *$ \\
\hline $\begin{array}{lll}\text { Digital } & \text { Security } & \text { and } \\
\text { Safety } & & \\
\end{array}$ & $0.819 * *$ & $\begin{array}{l}\text { Digital Security and } \\
\text { Safety }\end{array}$ & $0.780 * *$ \\
\hline $\begin{array}{l}\text { Digital Health and } \\
\text { Well-being }\end{array}$ & $0.724^{* *}$ & $\begin{array}{l}\text { Digital Health and } \\
\text { Well-being }\end{array}$ & $0.667 * *$ \\
\hline
\end{tabular}

** Function 20 at level 0.01 or less.

Table 3. shows that the correlation dimensions with total scores of the dimension which is belong to, function at a level of significance 0.01 , or 0.05 or less, all of them are positive values. This indicates that there is high degree of internal consistency and there is correlation between the phase and its dimensions, which reflects high degree of validity of questionnaire dimensions.

Table 4. Values of Alpha Cronbach coefficient of the study tool

\begin{tabular}{llll}
\hline Questionnaire Phase & Clauses No & $\begin{array}{l}\text { Value of reliability coefficient } \\
\text { Contribution } \\
\text { Degree of Twitter }\end{array}$ & $\begin{array}{l}\text { Contribution } \\
\text { SnapChat }\end{array}$ \\
\hline First Phase: Respect & 10 & 0.590 & 0.634 \\
Second Phase: Education & 10 & 0.611 & 0.658 \\
Third Phase: Security & 10 & 0.516 & 0.548 \\
$\begin{array}{l}\text { The general reliability of the study } \\
\text { tool (Study phases) }\end{array}$ & 30 & 0.788 & 0.822 \\
\hline
\end{tabular}

It is shown in table 4. that the reliability coefficients of Alpha Cronbach of the study phases are high, as the reliability coefficients of the first main axis "contribution degree of Twitter" ranged from (0.516 to 0.611), whereas the general reliability of the same axis has reached $(0.788)$. While the reliability coefficients of the second axis "contribution degree of SnapChat" ranged from (.548 to 658), and the general stability of the axis has reached (.822). Thereby, all of which are high reliability coefficients which indicates that the questionnaire enjoyed a high degree of reliability, therefore can be relied upon in the field application of the study.

\subsection{Statistics and Data Analysis Related to the Open Questionnaire on Twitter}

3.2.1 The Technological Skills Added by Twitter to Female Students at Imam Mohammed bin Saud Islamic University 
Table 5. The technological skills added by Twitter to female students at Imam Mohammed bin Saud Islamic University

\begin{tabular}{lll}
\hline The technological skills added by Twitter & Repetition & Percentage \\
\hline Quick writing & 11 & 20.1 \\
Quick communication with the outside world & 9 & 16.4 \\
Quick publication and free opinions expression & 12 & 21.9 \\
Speech abbreviation in one letter & 4 & 7.2 \\
Knowing recent news & 7 & 12.8 \\
Knowing everything new & 3 & 5.4 \\
Searching and getting information & 1 & 1.8 \\
Reducing letters number & 3 & 5.4 \\
Participating in education & 1 & 1.8 \\
Developing reading skills & 1 & 1.8 \\
knowing different cultures & 2 & 3.6 \\
Allow to add famous and normal people & 1 & 1.8 \\
Total & 55 & $100 \%$ \\
\hline
\end{tabular}

By reviewing the results shown in Table 5. it is found that (21.9\%) of total female students in the study sample believe that technological skill added by Twitter is quick publication and free opinions expression, whereas, (20.1\%) of total students believe that technological skill added by Twitter is quick writing. There are (16.4\%) of total students believe that technological skill added by Twitter is quick communication with the outside world, and (12.8\%) of total student believe that knowing recent news is the technological skill added by Twitter. While the rest of the study sample have varied and different opinions about the technological skills added by Twitter.

In some point, this result is consistent with the results of (Zahrani, 2013) study, which dealt with "the role of social networks in solving problems that faced by the students of practical education and their attitudes towards them". Results of Zahrani showed that Facebook contributed significantly in solving problems that are faced by the students of practical education during practices of practices, and the study community had positive attitudes towards using Facebook in solving problems faced by the students practical education.

\subsubsection{The Technological Advantages which Female Students had Found through Using Twitter}

Table 6. The technological advantage female students have found through using Twitter

\begin{tabular}{lll}
\hline $\begin{array}{l}\text { The technological advantages which female students have found through } \\
\text { using Twitter }\end{array}$ & Repetition & Percentage \\
\hline Quick and easy search & 9 & 19.1 \\
Surveying and benefits & 1 & 2.1 \\
Quick and easy communication with others & 8 & 17.1 \\
The rapid spread of the news and knowing all new & 13 & 27.7 \\
Speech abbreviation & 5 & 10.7 \\
Sharing useful tweets & 4 & 8.6 \\
Privacy & 2 & 4.2 \\
Increasing interdependence between people & 2 & 4.2 \\
Getting information quickly & 2 & 4.2 \\
Access to sources of information from religious and scientists & 1 & 2.1 \\
Total & 47 & $100 \%$ \\
\hline
\end{tabular}


In Table 6. It is clear that (27.7\%) of total female students in the study sample believe that the technological advantages which they had found through Twitter is the rapid spread of the news and knowing all new, whereas, $(19.1 \%)$ of total students in the study sample believe that the technological advantages which they had found through Twitter is quick and easy search. Also, there is (17.1\%) of total students in the study sample believe that the technological advantages which they had found through Twitter is quick and easy communication with others, and $(10.7 \%)$ believe that speech abbreviation is the technological advantages which they had found through Twitter. While the rest of the study sample have varied and different opinions about the technological advantages which they had found through Twitter, the previous table shows that. In some point, this result is consistent with the results of (Lindsey, 2015) study, which found that inserting and instilling technology was useful and positive in the college. In addition to the consolidation of extra experience on the topic of digital citizenship, which was outside the scope of previous experience of trainers and teachers, as there is determination for teachers to model digital citizenship in the classroom.

\subsubsection{The Technological Gaps that Female Students Wish that they Do Not Exist on Twitter}

Table 7. The technological gaps that female students wish that they do not exist on Twitter

\begin{tabular}{lcc}
\hline $\begin{array}{l}\text { The technological gaps that female students wish that they do not exist on } \\
\text { Twitter }\end{array}$ & Repetition & Percentage \\
\hline Hacking & 3 & 21.4 \\
Lack of access to the privacy of the individual & 5 & 35.8 \\
Private chats & 4 & 28.6 \\
Female or non-decent photos, and mockery of religious or some people & 1 & 7.1 \\
Detect locations & 1 & 1.1 \\
Total & 14 & $100 \%$
\end{tabular}

The results shown in Table 7. show that $(35.8 \%)$ of total female students in the study sample believe that technological gap that female students wish that they do not exist on Twitter is private chats, whereas (21.4\%) of students in the study sample believe that hacking is the technological gap that female students wish that they do not exist on Twitter. While the percentages of study sample individuals who found that there are technological gaps they wish that they do not exist in Twitter, were equal, which were Female or non-decent photos, and mockery of religious or some people with students in the study sample believe that technological gap is detecting locations. The rest of the study sample have varied and different opinions about The technological gaps that female students wish that they do not exist on Twitter, the above table shows that.

\subsection{Statistics and Data Analysis Related to the Open Questionnaire on SnapChat}

3.3.1 The Technological Skills Added by SnapChat to the Female Students at Imam Mohammed bin Saud Islamic University

Table 8 . The technological skills added by SnapChat to female students at Imam Mohammed bin Saud Islamic University

\begin{tabular}{lll}
\hline $\begin{array}{l}\text { The technological skills added by SnapChat to female students at Imam } \\
\text { Mohammed bin Saud Islamic University }\end{array}$ & Repetition & Percentage \\
\hline Watching events that happen all over the world & 4 & 16.6 \\
The participation in activities of others & 6 & 25.1 \\
Shooting events in time & 3 & 12.4 \\
Adding more and new knowledge & 1 & 4.2 \\
Adding symbols & 1 & 4.2 \\
Developing audio skills & 1 & 4.2 \\
Not to distract & 1 & 4.2 \\
\hline
\end{tabular}




\begin{tabular}{lll}
\hline Following famous people & 1 & 4.2 \\
Quick responds & 1 & 4.2 \\
Filming & 1 & 4.2 \\
Events transmissions & 1 & 4.2 \\
Knowing new cultures & 1 & 4.2 \\
Knowing new information & 2 & 8.2 \\
Total & 24 & $100 \%$ \\
\hline
\end{tabular}

By looking at Table 8 , it is found that $(25.1 \%)$ of total female students in the study sample believe that the technological skill added by SnapChat is The participation in activities of others, whereas, $(16.6 \%)$ of total female students in the study sample believe that the technological skill added by SnapChat is Watching events that happen all over the world. Also, (12.4\%) of total female students in the study sample believe that Shooting events in time is the technological skill added by SnapChat, and there is $(8.2 \%)$ of total female students in the study sample believe that Knowing new information is the technological skill added by SnapChat. The rest of the study sample have varied and different opinions about the technological skills added by SnapChat, the previous table shows that. This result, in some point, is consistent with (Enezi and Majadi, 2013) study, which dealt with (the realty of using Facebook and Twitter by female students of Basic Education in Kuwait towards mathematics), as it concluded some results, most important of which was that students of basic education, specially, in the practical disciplines are interested in social networks like Facebook and Twitter, as they are a source of various cultures and it facilitates their communication with their professors in college, but they also have the technical potential to interact with these programs and offer technical abilities to express their views. Students of the college of basic Education in the scientific disciplines are interested to keep pace with developments technology and the use of its applications in teaching and learning to enhance the academic achievement.

3.3.2 What are the Technological Advantages that the Female Students had Found through Using SnapChat

Table 9. The technological advantages which female students had found through using SnapChat

\begin{tabular}{lll}
\hline $\begin{array}{l}\text { The technological advantages which female students had found through } \\
\text { using SnapChat. }\end{array}$ & Repetition & Percentage \\
\hline Reaching to people quickly and easily & 5 & 31.3 \\
participation in activities of others & 1 & 6.2 \\
Communicating with friends & 1 & 6.2 \\
Communicating with friends easily & 2 & 12.7 \\
Knowing the cultures of nations & 4 & 25 \\
Free time occupation & 1 & 6.2 \\
Photos & 1 & 6.2 \\
Reliability & 1 & 6.2 \\
Total & 16 & $100 \%$ \\
\hline
\end{tabular}

Table 9 reveals that $(31.3 \%)$ of total female students in the study sample believe that the technological advantage which female students have found through using SnapChat is reaching to people quickly and easily, whereas, $(25 \%)$ of total female students in the study sample believe that the technological advantage which female students had found through using SnapChat is knowing the cultures of nations. There is $(12.7 \%)$ of total female students in the study sample believe that communicating with friends easily is that the technological advantage which female students had found through using SnapChat. Eventually, percentages of the study sample individuals who believe that the technological advantage which female students had found through using SnapChat are participation in activities of others, communicating with friends, free time occupation, photos and reliability, were equal, this was by (6.2\%) for each one. This results are consistent with (Maleeh, 2013) study, 
which was entitled (how extent is the use of social media in the field of social movements), where the study found that that the most prominent uses of the study individuals for networks of communication are as follows (communicate with others, viewed broadly the world and the news, following the news of their interest, exchange ideas with others, to participate in social issues, gathering people who has common interests and help to mobilize support on a particular issue.

3.3.3 The Technological Gaps which the Female Students Wish that they do not Exist on SnapChat

Table 10. The technological gaps that female students wish that they do not exist on SnapChat

\begin{tabular}{lll}
\hline $\begin{array}{l}\text { The technological gaps that female students wish that they do not exist } \\
\text { on SnapChat }\end{array}$ & Repetition & Percentage \\
\hline Participation in activities of others & 1 & 3.1 \\
Losing privacy & 17 & 53.1 \\
Ease hacking & 2 & 6.3 \\
Posting photos and videos & 6 & 18.8 \\
More resolution and more writing & 3 & 9.4 \\
Detecting locations & 1 & 3.1 \\
Programs for saving images and videos & 1 & 3.1 \\
Using by children & 1 & 3.1 \\
Total & 32 & $100 \%$ \\
\hline
\end{tabular}

It is found as Table 10. shows that $(53.1 \%)$ of total female students in the study sample believe that the technological gap that female students wish that they do not exist on SnapChat is losing privacy, while, (18.8\%) of total female students in the study sample believe that the technological gap that female students wish that they do not exist on SnapChat is posting photos and videos. Besides, $(9.4 \%)$ of total female students in the study sample believe that more resolution and more writing is the technological gap that female students wish that they do not exist on SnapChat, whereas, (6.3\%) of total female students in the study sample believe that ease hacking is the technological gap that female students wish that they do not exist on SnapChat. Eventually, percentages of the study sample individuals who believe that the technological gaps that female students wish that they do not exist on SnapChat are detecting locations, programs for saving images and videos and using by children, were equal, with (3.1\%) for each one.

Thus, this study concludes that SnapChat and Twitter contribute to reinforcing digital citizenship meaning from the viewpoint of female students at Imam Mohammed bin Saud Islamic University in Riyadh as the results above show. Both sites have added technology skills to the students such as publishing quickly, Expression, Freedom to express an opinion, and communicate quickly with all over the world. The SnapChat and Twitter have not digital security feature in terms of positioning, ease of penetration and save the private clips. The finding of the study are of importance and practical significance that these findings can be taken in consideration to activate the role of the university in increasing the awareness towards the digital citizenship of social networks in general and Twitter and SnapChat in particular. The two Social Networks, Twitter and SnapChat, can be used in popularizing and authenticating digital citizenship for female students. The advantages of the two social networks can be also utilized to increase the technological awareness in the university environment and employing them in education as these sites attract the attentions and interest of students in the academic environment and enjoy popularity as the findings above show. These networks can be useful in the educational feedback and achieving digital communication perception between students and the faculty members. Utilizing the advantages of the two social networks to increase the technological culture by implementing it in the administrative process relevant to female students such as publishing the timetable and results and other instructions can be one of the practical importance of the finding of this study.

On the basis of such findings, the study also recommends providing he female

students with the digital research skills by utilizing the advantages of the two social networks, encouraging students to find solutions for the lacuna in these social networks for privacy and knowledge purposes, strengthening the relationship between university life environment and female students' life interests by starting 
groups of common interests for female students, distributing questionnaires for female students regarding the advantages and disadvantages of these two social networks to increase the awareness towards these networks, constructing a general strategy, that involve faculty members, students, family and social institutions, in order to spread awareness of the digital citizenship by using them. The strategy should be integrated to the general goals of education, adopting digital citizenship as a course in the syllabus of education in all the places of education, and, more importantly, the outcomes of this study should lead to increasing the awareness of female students of the cybercrimes and the law laid down against hacking which was approved by the cabinet council decree No. 79 dated 07-03-1428 A.H.

The present study was limited to addressing the issue of the role of social media in promoting the digital citizenship among the female students at Imam Mohammed bin Saud Islamic University in Riyadh, therefore, it is important to carry a further similar research in other universities of KSA with comparison to this study. This study also opens the gates for other researches to conduct a similar study on public education and comparing it to the present study for establishing a general frame that will help in starting a course on digital citizenship. A further study is recommended on 'The impact of employing Twitter and SnapChat in authenticating the digital citizenship concept for secondary school female students in Riyadh'. A possible future research can address the issue of 'The extent of availability of digital citizenship concept in the preparatory education'. The study also recommends another research on 'The extent of using digital citizenship concepts for the secondary education teachers of social studies courses' in order to respond to questions left beyond the limitations of the present study.

\section{References}

Del Castillo, M. (2012). The App with Self-destructing Messages Launches on Android. Retrieved from http://upstart.bizjournals.com

Enezi, Y., \& Majadi, H. (2013). The Reality of Using Social Networks, Facebook, Twitter for Education College of Kuwait's Female Students towards Mathematics. Scientific Magazine, 29.

Lenhart, A., Purcell, K., Smith, A., \& Zickuhr, K. (2010). Social media and mobile internet use among teens and young adults. Retrieved from http://www.pewinternet.org/Reports/2010/Social-Media-and-Young-Adults.aspx

Lindsey, L. (2015). Preparing Teacher Candidates for 21st Century Classrooms: A Study of Digital Citizenship. Doctoral Dissertation. Arizona State University, Arizona.

Lu, V. (2014). Engaging Families in Digital Citizenship: A Workshop for Families in Middle School. Master Dissertation. Northridge: California State University.

Maleeh, S. (2013). The Use of Social Media in the Field of Social Movements: A Study Applied on the Teachers of Social Science College at the Islamic University of Imam Mohammed bin Saud. Riyadh, Central Library of King Salman Press.

Manjaji, R. (2014). Six Snapchat Experiments to Engage Students. Retrieved from http://www.educationpost.com.hk.

Maslamani, L. (2014). Education and Digital Citizenship: A Proposed Vision. Education World Journal, 47(2), 17-94.

Ribble, M. (2012). Digital Citizenship at Schools. Trans. Arab Education Office for Gulf Countries. Arab Education Office for Gulf Countries Press.

Ribble, M. (2004). Digital Citizenship Addressing Appropriate Technology Behavior. Retrieved from https://www.iste.org

Ribble, M. (2014). Essential Elements of Digital Citizenship. Retrieved from https://www.iste.org

Ribble, M. (2015). Nine Elements of Digital Citizenship. Retrieved from http://www.digitalcitizenship.net

Shakra, K. (2014). New Media Social Networks. Oman: Osama Publishing House.

Trilling, B., \& Fadel, C. (2009). 21st Century Skills: Learning for Life in Our Times. San Francisco, CA: John Wiley \& Sons.

Wilson, M. (2015). Using Snapchat in Higher Education. Retrieved from http://convergeconsulting.org

Zahrani, A. (2013). The Role of Social Media Websites in Solving the Problems that the Students of the Operational Educational Face and their Views Toward that. OM Al-Kura. 
Zakawah, A. (2015). The Role of Schools in the Development of the Values of Citizenship From the Viewpoint of Secondary Educational Teachers. Arbak Magazine, 17, 51-62.

\section{Copyrights}

Copyright for this article is retained by the author(s), with first publication rights granted to the journal.

This is an open-access article distributed under the terms and conditions of the Creative Commons Attribution license (http://creativecommons.org/licenses/by/4.0/). 